\title{
From telecollaboration to virtual exchange: state-of-the-art and the role of UNICollaboration in moving forward ${ }^{1}$
}

\author{
Robert O'Dowd²
}

Abstract

Delecollaboration, or 'virtual exchange', are terms used to refer to the engagement of groups of learners in online intercultural interactions and collaboration projects L with partners from other cultural contexts or geographical locations as an integrated part of their educational programmes. In recent years, approaches to virtual exchange have evolved in different contexts and different areas of education, and these approaches have had, at times, very diverse organisational structures and pedagogical objectives. This article provides an overview of the different models and approaches to virtual exchange which are currently being used in higher education contexts. It also provides a short historical review of the major developments and trends in virtual exchange to date and describes the origins of the UNICollaboration organisation and the rationale behind this journal.

\section{Keywords: virtual exchange; telecollaboration; online intercultural exchange; computer mediated communication; intercultural communication; internationalisation.}

1. Parts of this article were previously published in an article by the same author (O'Dowd, 2017) which appeared in the TLC Journal - Training Language \& Culture, 4(2). They have been reproduced with permission.

2. University of León, León, Spain; robert.odowd@unileon.es

Robert O'Dowd has published widely on the application of collaborative online learning in university education. His most recent publication is the co-edited volume Online Intercultural Exchange Policy, Pedagogy, Practice, for Routledge. He is currently the lead researcher on the Erasmus+ KA3 project, Evaluating and Upscaling Telecollaborative Teacher Education (EVALUATE) (http://www.evaluateproject.eu/). He was the founding president of the UNICollaboration organisation (www. unicollaboration.org).

How to cite this article: O'Dowd, R. (2018). From telecollaboration to virtual exchange: state-of-the-art and the role of UNICollaboration in moving forward. Journal of Virtual Exchange, 1, 1-23. Research-publishing.net. https://doi.org/10.14705/rpnet.2018.jve.1 


\section{Introduction}

The launch of a UNICollaboration academic journal is a significant event for many reasons. First of all, it is the first journal which is exclusively dedicated to the research and practice of pedagogicallystructured online collaborative learning initiatives between people in different cultural contexts or geographical locations. Second, the journal represents an attempt to create a cross-disciplinary approach to virtual exchange practise and research.

Although the origins of the UNICollaboration organisation may lie firmly in the fields of applied linguistics and foreign language education, the colleagues working in this initiative are keenly aware that virtual exchange offers learning benefits which are relevant to learners across all disciplines. We are also aware that there are many exciting virtual exchange initiatives underway in contexts outside of foreign language education (see, for example, the X-Culture and Collaborative Online International Learning (COIL) models described later in this paper) and that both the practice and research of virtual exchange will benefit from a cross-disciplinary approach.

This article begins by looking at some of the issues in the terminology and definitions in the area, before moving on to give an overview of the different models and approaches to virtual exchange which are currently being used in higher education contexts. It also carries out a short historical review of the major trends and advances in virtual exchange to date and concludes by looking at recent developments and addressing some of the challenges and barriers which practitioners and researchers continue to encounter.

\section{Terminology and definitions}

Over the past three decades, approaches to virtual exchange have evolved in different contexts and different areas of education, and these approaches have happened, to a great extent, in blissful isolation of one another. One of the results of this has been that the activity has assumed different monikers and terminology depending on the educational context and the pedagogical focus of its practitioners. For example, over the past number of years, different incarnations of the activity have been referred to as telecollaboration (Belz, 2001; Warschauer, 1996), online intercultural exchange (O’Dowd, 2007; O’Dowd \& Lewis, 2016), virtual exchange (Helm, 2015), (COIL) (Rubin, 2016; Schultheis Moore \& Simon, 2015), internet-mediated intercultural foreign language education (Belz \& Thorne, 2006), globally networked learning environments (Starke-Meyerring \& Wilson, 2008), and e-tandem (O’Rourke, 2007) or teletandem (Leone \& Telles, 2016). 
This mushroom-like emergence of virtual exchange initiatives in different academic areas using different terminology has had both positive and negative consequences. On the positive side, it has meant that the basic methodology of pedagogically-structured online collaborative learning between groups of learners in different cultural contexts or geographical locations has been applied in a myriad of ways and has been shown to be adaptable to different pedagogical objectives and learning contexts.

However, the heterogeneity of the activity has meant that practitioners and researchers focussing on one form of virtual exchange (for example, telecollaborative learning in foreign language education) have been unaware of the practices and the research outcomes of similar initiatives in other areas of education (and vice versa). It is striking, for example, that Starke-Meyerring and Wilson (2008) in their volume on globally networked learning environments lament that their potential "to inspire multilingual interaction as well as language learning remains yet to be explored” (p. 225). For authors to suggest this is the case at a time when a huge body of research and practice literature already existed about foreign language approaches to virtual exchange (e.g. Belz, 2001, 2003; Warschauer, 1995, 1996) simply demonstrates the lack of communication and collaboration which exists between researchers in this field.

A second challenge of the multiple approaches and terminology has been the resulting difficulty in promoting and disseminating the activity among educators and decision makers who are unfamiliar with the concept. Rubin (2016), one of the pioneers of the COIL initiatives in the US, regrets that "[o] ne of the problematics of this format is that it is called by so many different names, thereby making it harder for the practice to be more commonly understood and implemented” (p. 263).

It is against this background that the original architects of the UNICollaboration organisation and their collaborators from other initiatives have struggled with the challenge of finding terminology that will be acceptable to as many practitioners and researchers as possible. As mentioned above, the majority of the colleagues originally involved in this initiative come from the field of foreign language education, and the bulk of publications and presentations in this field have referred to the activity as telecollaboration. However, outside this field, the term telecollaboration is largely unknown, and to many ears it is likely to sound quite dated and opaque.

While the term telecollaboration is being questioned in some quarters, the term virtual exchange seems to be used increasingly in a wide range of contexts. Not only is it the preferred term of educational organisations such as Soliya and Sharing Perspectives, but it is also the term being used by foundations and governmental and intergovernmental bodies such as the Stevens Initiative, the Bureau of Educational and Cultural Affairs in the US, and the European Commission. The following 
quotation by the European Commissioner Tibor Navracsics on the 12th of July 2016, where he discusses expanding the pre-existing Erasmus+ physical mobility programmes, highlights the growth in awareness among policy makers in Europe to the activity and to the term virtual exchange:

"I want to complement [Erasmus+] with virtual youth exchanges. These would allow young people from the EU and neighbourhood countries to learn about and understand cultural differences, while improving their soft skills, including foreign languages and teamwork. I want to involve 2,000 young people in this 'Erasmus Virtual Exchange pilot project' by the end of 2017, and 200,000 young people by the end of 2019” (Navracsics, 2016, cited in European Commission, 2017, p. 24).

Therefore, in order to reflect both our origins in foreign language telecollaborative research and practice and also our future as an international, cross-disciplinary organisation open to collaboration with policy and research initiatives, our academic organisation was named UNICollaboration - the Cross-Disciplinary Organisation for Telecollaboration and Virtual Exchange in Higher Education. This, I believe, recognises the validity of the huge amount of research which has been carried out under the title of 'telecollaboration', but also will help to establish 'virtual exchange' as an umbrella term for our field of practice. Figure 1 provides an overview of the main terminology used in this area and situates virtual exchange as a compromise umbrella term to cover all these approaches ${ }^{3}$.

\section{Figure 1. An overview of terminology used to refer to virtual exchange initiatives}

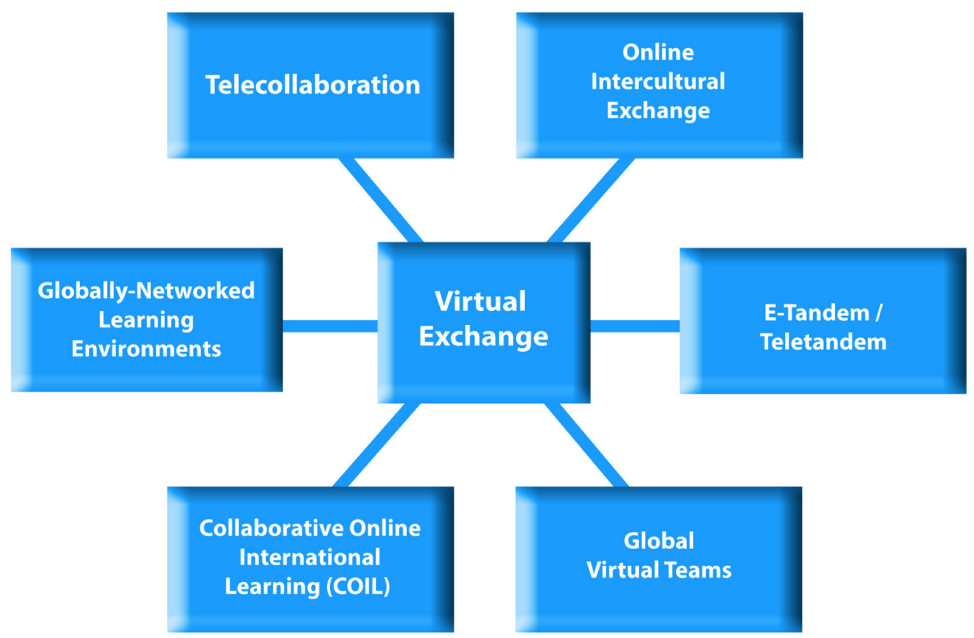

3. However, it is important to differentiate between virtual mobility and virtual exchange. While virtual exchange refers to the different approaches to online intercultural exchange projects in education, virtual mobility refers to students using online platforms and tools to take courses at a distant university. 
It is worth noting that the term virtual exchange does not lend itself for use as an adjective, and for that reason, I find the use of the adjective telecollaborative in cases such as telecollaborative interaction and telecollaborative learning outcomes as being more accurate than, merely, virtual interaction and virtual learning outcomes - which may imply something which occurs online but not necessarily as part of a virtual exchange initiative.

In relation to defining what virtual exchange actually involves, there are probably as many definitions as there are terms. However, the elements which appear to be common to most interpretations of Virtual Exchange initiatives are reflected in the following: virtual exchange involves the engagement of groups of learners in extended periods of online intercultural interaction and collaboration with partners from other cultural contexts or geographical locations as an integrated part of their educational programmes and under the guidance of educators and/or expert facilitators. This is perhaps a more limiting definition than that offered by the Virtual Exchange Coalition, which states that "virtual exchanges are technology-enabled, sustained, people-to-people education [programmes]", and it may also risk excluding models which operate outside of formal education. However, I believe it captures the essential commonalities of the models of virtual exchange which will be looked at in the following section.

\section{Differing approaches to virtual exchange}

The first examples of online collaborative projects between classrooms around the globe began to appear within a few years of the emergence of the internet. Early reports include the work of Tella (1991), the Orillas Network (Cummins \& Sayers, 1995), the AT\&T Learning Circles (Riel, 1997), as well as more in-depth research studies into foreign language exchanges (Eck, Legenhausen, \& Wolff, 1995). The publication Virtual Connections: Online Activities for Networking Language Learners (Warschauer, 1995) included a collection of 'cross-cultural communication' projects which reported on foreign language students creating personal profiles, carrying out surveys, and examining cultural stereotypes with distant partners. Around this time, a number of websites, including Intercultural Email Classroom Connections (IECC) and e-tandem, also became available online in order to link up classrooms across the globe and to provide practitioners with activities and guidelines for their projects. The IECC LISTSERV was established by university professors at St. Olaf College in Minnesota, US, and functioned as one of the first 'matching services' for teachers who wanted to connect their students in email exchanges with partner classes in other countries and in other regions of their own country. Between 1992 and 2001, IECC distributed over 28,000 requests for email partnerships (Rice, 2005). The e-tandem server was aimed at matching learners of foreign languages and was supported by a network of research and project work carried at Bochum University in Germany and 
Trinity College in Dublin (O’Rourke, 2007). Meanwhile, practitioners such as Ruth Vilmi in Finland and Reinhard Donath in Germany helped to make the activity better known by publishing practical reports of their students' work online. Vilmi's (1994) work focussed on online collaboration between technical students at universities across Europe, while Donath provided German secondary school foreign language teachers with a wide range of resources and information about how projects could be integrated into the curriculum (Donath \& Volkmer, 1997).

One possible categorisation of the different initiatives involves differentiating between subjectspecific virtual exchanges, shared syllabus approaches, and service-provider approaches. Each of these will now be looked at in some detail (Table 1).

Table 1. Different approaches to virtual exchange in higher education

\begin{tabular}{|c|c|c|c|}
\hline $\begin{array}{l}\text { Approach to virtual } \\
\text { exchange }\end{array}$ & $\begin{array}{l}\text { Associated terminology } \\
\text { and well-known examples }\end{array}$ & Main Characteristics & Current situation \\
\hline $\begin{array}{l}\text { Subject-specific virtual } \\
\text { exchange (1): } \\
\text { Foreign language } \\
\text { learning initiatives }\end{array}$ & $\begin{array}{l}\text { Common Terminology: } \\
\text { "Telecollaboration", } \\
\text { "Online intercultural exchange" } \\
\text { "E-tandem" } \\
\text { "Teletandem" } \\
\text { Examples: } \\
\text { Cultura } \\
\text { Teletandem }\end{array}$ & $\begin{array}{l}\text { Development of foreign } \\
\text { language competence, } \\
\text { intercultural communicative } \\
\text { competence and } \\
\text { digital competence } \\
\text { Practitioner-led initiatives } \\
\text { Often bilingual }\end{array}$ & $\begin{array}{l}\text { A large body of research } \\
\text { and practice publications } \\
\text { An online platform for } \\
\text { finding partnerships, } \\
\text { tasks and training: } \\
\text { www.unicollaboration.eu } \\
\text { Recent establishment of } \\
\text { an academic organisation } \\
\text { - UNICollaboration }\end{array}$ \\
\hline $\begin{array}{l}\text { Subject-specific virtual } \\
\text { exchange (2): } \\
\text { Business studies initiatives }\end{array}$ & $\begin{array}{l}\text { Common Terminology: } \\
\text { "Global virtual teams" } \\
\text { Examples: } \\
\text { X-Culture }\end{array}$ & $\begin{array}{l}\text { Preparation of online } \\
\text { intercultural skills necessary } \\
\text { for the workplace } \\
\text { Practitioner-led initiatives } \\
\text { Data from exchanges shared } \\
\text { for research purposes }\end{array}$ & $\begin{array}{l}\text { Growing body of research } \\
\text { and practice publications } \\
\text { Growing community } \\
\text { of practice: } \\
\text { http://x-culture.org/ }\end{array}$ \\
\hline Service-provider approaches & $\begin{array}{l}\text { Common Terminology: } \\
\text { These were the first } \\
\text { initiatives to coin the term } \\
\text { "Virtual exchange" } \\
\text { Examples: } \\
\text { iEarn } \\
\text { Global Nomads } \\
\text { Soliya } \\
\text { Sharing Perspectives }\end{array}$ & $\begin{array}{l}\text { Development of intercultural } \\
\text { awareness, critical thinking, } \\
\text { and digital literacies } \\
\text { Facilitator-led exchanges } \\
\text { 'Outsourced' by } \\
\text { universities to service- } \\
\text { providers who provide } \\
\text { platform, partners etc. }\end{array}$ & $\begin{array}{l}\text { Many of the organisations } \\
\text { are working together in the } \\
\text { Virtual Exchange Coalition }\end{array}$ \\
\hline
\end{tabular}




\begin{tabular}{|l|l|l|l|}
\hline Shared syllabus approaches & $\begin{array}{l}\text { Common Terminology: } \\
\text { "COIL" } \\
\text { "Globally networked } \\
\text { learning environments" }\end{array}$ & $\begin{array}{l}\text { Addition of international } \\
\text { perspectives to } \\
\text { course syllabus } \\
\text { Example: } \\
\text { Development of digital } \\
\text { competence and } \\
\text { intercultural competence } \\
\text { Networked Learning } \\
\text { in the Humanities } \\
\text { (COIL) }\end{array}$ & $\begin{array}{l}\text { In the US: } \\
\text { COIL Institute for Globally } \\
\text { Networked Learning } \\
\text { in the Humanities }\end{array}$ \\
\hline
\end{tabular}

\subsection{Subject-specific virtual exchange (1): e-tandem, telecollaboration, and other foreign language learning initiatives}

It is not surprising that one of the disciplines to most eagerly take up virtual exchange as a learning tool has been foreign language education. From the beginnings of the internet in the early 1990's, foreign language educators have seen the potential of connecting language learners with counterparts in other countries in order to engage them in interaction with speakers of other languages and to give them semi-authentic experiences of communicating in these languages.

In foreign language education, virtual exchange has been referred to principally as telecollaboration (Belz, 2003), telecollaboration 2.0 (Guth \& Helm, 2010), e-tandem (O’Rourke, 2007) or online intercultural exchange (O'Dowd, 2007; O’Dowd \& Lewis, 2016), and over the past 20 years it has gone on to become an integral part of Computer-Assisted Language Learning (CALL) or Network-Based Language Teaching (NBLT) (Kern, Ware, \& Warschauer, 2008).

Virtual exchange in foreign language education has traditionally taken the form of one of two models - each one reflecting the principal learning approaches prevalent in foreign language education at the time. The first well-known model was e-tandem, which focussed on fostering learner autonomy and learners' ability to continue their language learning outside of the language classroom. The second model is usually referred to as intercultural telecollaboration or online intercultural exchange (O'Dowd, 2007) and reflects the emphasis in the late 1990's and early 2000's on intercultural and sociocultural aspects of foreign language education.

In the e-tandem model (O'Rourke, 2007), two native speakers of different languages communicate together with the aim of learning the other's language, and messages are typically written 50\% in the target and 50\% in the native language, thereby providing each partner with an opportunity to practise their target language and, at the same time, provide their partner with authentic input. 
These exchanges are also based on the principle of autonomy, and the responsibility for a successful exchange rests mainly with the learners, who are expected to provide feedback on their partners' content and/or on their foreign language performance. In this sense, tandem partners take on the role of peer tutors who interact together about both content and linguistic issues, proposing to their partners, when appropriate, alternative formulations in the target language. The role of the class teacher in the e-tandem model is usually minimal. For example, learners are often encouraged to take on responsibility for finding their own themes for discussion, correcting their partners' errors, and keeping a learner diary or portfolio to reflect on their own learning progress.

The example below of an American student writing an email to her partner in Spain illustrates many of the key aspects of a typical e-tandem 4 . The American student begins by writing in English and talking to her Spanish partner for his recent message. She then takes on the role of peer-tutor and provides some corrections of Pablo's English. Although she does not provide detailed grammatical feedback, she is able to suggest alternative formulations and she is sure to praise him for his writing in his foreign language. In the second part of the message, she then takes on the role of Spanish learner and tells her partner about student life in New York. It is likely that in the following message, Pablo will respond to Elena, providing some corrections to her Spanish and continuing the conversation.

Hey Pablo!

It was great to receive your letter. I was so happy to see that you responded to my questions. Thank you. Your responses were very informative and definitely showed me that family life in Spain was not all I'd expected it to be (I was surprised, for example, that your family is not religious. I assumed that most families in Spain are, and I'm sure you have many assumptions about life in America as well).

Your English is very good. There are only a few problems that I have to correct. Some of your sentences are too long, and would make more sense if you separated them into two or three sentences instead. For example, "My parents are not divorced in Spain there are very few cases of divorced" could be rewritten as "My parents are not divorced. In Spain there are very few cases of divorce". Your letter was great and made sense despite these things. Good work.

Las fiestas en the ciudad de Nueva York son muy locas y emocionantes. Voy a las discotecas con mis amigas los jueves, los viernes, o los sabados. Vamos a los bars tambien. Nosotros volvemos a nos salons de dormitorio a las cuatro de la manana. Queremos bailar a las

4. Example taken from author's research data (reprinted with permission from the participant). 
discotecas. Necesita tener veintiuno anos por beber el alcohol pero la mayoria de estudiantes en las universidades tenen los “fake IDs” y ellos beben el alcohol...

Although the model is now over 20 years old, e-tandem continues to be a very popular form of virtual exchange in foreign language education. A large amount of research on the outcomes of e-tandem learning continue to appear in the literature (Bower \& Kawaguchi, 2011; Vinagre \& Muñoz, 2011). Browsing the many partner-searches which appear on the http://uni-collaboration.eu/ platform for class matching reveals that many practitioners continue to look for e-tandem style exchanges. In the first example below, a teacher looks for partners for a Portuguese-English e-tandem exchange (Figure 2), while in the second example a teacher of Spanish as a foreign language is looking for a partner class of native speakers of Spanish and (Figure 3).

\section{Figure 2. Portuguese-English e-tandem exchange ${ }^{5}$}

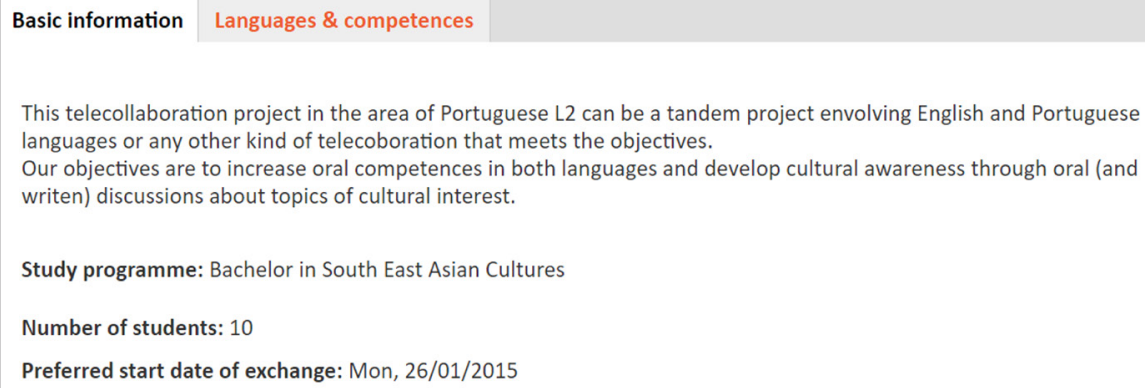

\section{Figure 3. Teacher of Spanish looking for a partner class of native speakers of Spanish ${ }^{6}$}

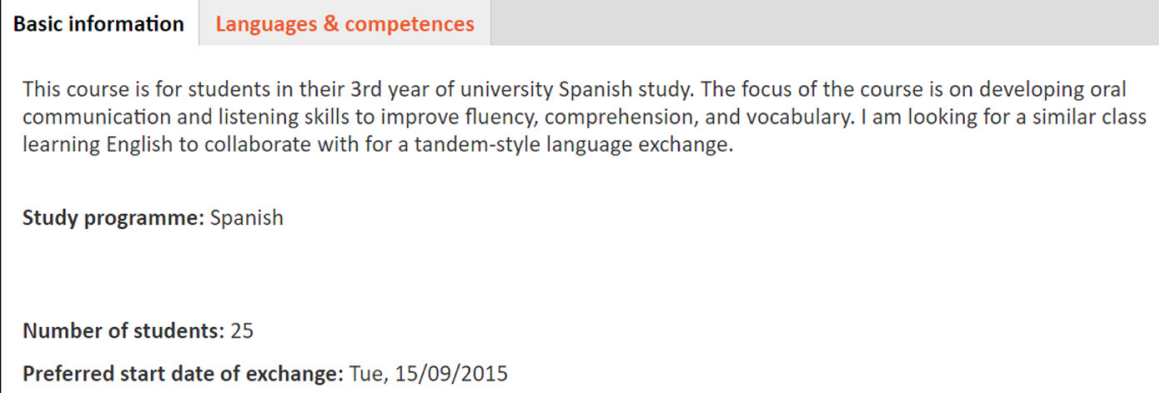

Number of students: 25

Preferred start date of exchange: Tue, 15/09/2015

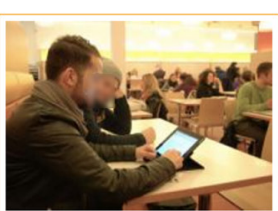

5. http://www.unicollaboration.eu/node/1073

6. http://www.unicollaboration.eu/node/1125 
In the late 1990's, a second model or approach to Virtual Exchange in foreign language education began to appear which was characterised by a stronger focus on intercultural aspects of language learning and communication and by a greater integration of the online exchanges into classroom activity. This form of virtual exchange was to become broadly known as 'telecollaboration'. The term was coined by Mark Warschauer (1996) in his publication Telecollaboration and the Foreign Language Learner, and a special edition of the journal Language Learning \& Technology was dedicated to the subject in 2003 where Belz identified the main characteristics of foreign language telecollaboration to be "institutionalised, electronically mediated intercultural communication under the guidance of a languacultural expert (i.e. a teacher) for the purposes of foreign language learning and the development of intercultural competence” (Belz, 2003, p. 2).

The telecollaborative model of virtual exchange strives to integrate the online interaction comprehensively into the students' foreign language programmes and involves international classto-class partnerships in which intercultural projects and tasks are developed by the partner teachers in the collaborating institutions. For example, students' face-to-face contact classes with their teachers are where online interaction and products (e.g. videos, blogs, etc.) are prepared, analysed, and reflected upon with the guidance of the teacher. Foreign language telecollaboration also places the emphasis of the exchanges on developing intercultural awareness and other aspects of intercultural communicative competence, in addition to developing linguistic competence (Furstenberg, Levet, English, \& Maillet, 2001).

There is great variety in the types of tasks which educators have used to develop intercultural approaches to telecollaboration. Some of the better known tasks involved requiring students to work together with their international partners to produce websites or presentations based on comparisons of their cultures. Belz (2002), for example, reports on a US-German exchange which involved developing a website which contained bilingual essays and a bilingual discussion of a cultural theme such as racism or family. Another popular intercultural task for telecollaborative exchanges has been the analysis of parallel texts. Belz (2005) defines parallel texts as "linguistically different renditions of a particular story or topic in which culturally-conditioned varying representations of that story or topic are presented” (n.p.). Popular examples of parallel texts which have been used in telecollaborative exchanges include the American film Three men and a baby and the French original Trois hommes et un couffin.

A further intercultural task adapted to telecollaboration was the application of ethnographic interviewing in synchronous online sessions. O’Dowd (2006) trained a group of German English as a foreign language students in the basic techniques of ethnographic interviewing, and the students then carried out interviews with American informants in the US using group-to-group video 
conferencing sessions and one-to-one email exchanges before writing up reflective essays on their findings. The combination of synchronous and asynchronous tools allowed the students to develop different aspects of their intercultural competence. Video conferencing was seen as developing students' abilities to interact with members of the target culture under the constraints of real-time communication and to also elicit, through a face-to-face dialogue, the concepts and values which underlie their partners' behaviour and their opinions. However, email was employed to both send and receive much more detailed information on the two cultures' products and practices as seen from the partners' perspectives. In other words, email was suited to foster cultural knowledge, while video conferencing supported the development of students' intercultural negotiating skills.

The end of the 2010's has seen foreign language virtual exchange gradually diverge into two paths. The first of these paths leads telecollaborative exchanges away from formal language learning and the definition of virtual exchange presented in these pages. Instead, it engages learners in language and cultural learning experiences by immersing them in specialised online interest communities or environments that focus on specific hobbies or interests. Thorne (2010) describes this form of telecollaborative learning as "intercultural communication in the wild" (p. 144) and speculates that it may be "situated in arenas of social activity that are less controllable than classroom or organised online intercultural exchanges might be, but which present interesting, and perhaps even compelling, opportunities for intercultural exchange, agentive action, and meaning making” (p. 144).

The second, alternative path in foreign language virtual exchange involves attempts to integrate telecollaborative networks more comprehensively in formal education. The argument here is that if virtual exchange is such a valuable learning experience, then it should not be used as an 'addon' activity but rather as a recognised, credit-carrying activity which is valued and supported by university management. Based on this belief, reports have emerged of how universities are integrating virtual exchange into their study programmes (O’Dowd, 2013), using alternative credit systems for students' telecollaborative work (Hauck \& MacKinnon, 2016), and developing competence models for telecollaborative learning (Dooly, 2016) and for teachers engaged in telecollaborative exchanges (O’Dowd, 2015).

\subsection{Subject-specific virtual exchange (2): X-culture and other business studies initiatives}

Another discipline which has recognised the relevance and potential of virtual exchange is business studies, in particular in the areas of international business and international marketing. In modern business contexts, online communication is widely considered as offering a cost effective way of conducting business, as a manner to reduce power differences in team work, and to enable physically disadvantaged employees to have greater access to the virtual environment than the physical 
workspace (Heller, Laurito, \& Johnson, 2010). As online communication becomes increasingly common in many organisations, a growing number of educators are looking to virtual exchange as a tool to prepare students of business studies to successfully work and collaborate online with colleagues and customers in other locations. The central interest here is in developing in students the necessary competences to work in what are commonly described as Global Virtual Teams (GVTs) and to give them first-hand experience in online international collaboration in professional contexts. GVTs are defined as "geographically dispersed teams that use internet-mediated communication to collaborate on common goals, and typically consist of members who have diverse cultural backgrounds and who have not previously worked together in face-to-face settings” (Taras et al., 2013, p. 415).

A review of practice in this area would suggest that virtual exchange initiatives are, in comparison to foreign language telecollaboration, relatively scarce and under-researched, but the reports that do exist provide an insight into how virtual exchange is being introduced into the discipline. Duus and Cooray (2014), for example, describe a project for students of marketing which brings together business students in the UK and India to take part in a simulation which involves working in online virtual teams and setting up a new business in India. Lindner (2016) reports on an exchange between business studies students at the University of Paderborn in Germany and Masaryk University in Brno in the Czech Republic which involved students collaborating online with their international partners to create a website which compared a product, service, or managerial innovation across two cultures. Osland et al. (2004) present the Globally Distant Multiple Teams project which brought groups of German, Austrian, and American students together in virtual teams in online communication using emails, chat rooms, and other online communication tools. Students were asked to prepare a report or develop a website comparing a product, service, or organisational feature across their countries. For example, one group compared differing marketing approaches and consumer attitudes related to soft drinks in Germany and the US.

However, probably the largest virtual exchange initiative emerging from business studies is the X-Culture project. X-Culture was launched in 2010 by Dr. Vas Taras of University of North Carolina at Greensboro, US, when he began to look for a partner class for his international business course and realised the interest among colleagues in such online collaborative projects. In the first year of exchanges, universities from seven countries took part in X-Culture exchanges, but by 2015, almost 4,000 master's and undergraduate students from over 100 universities in 40 countries were participating in the initiative. Since 2013, a number of companies have worked together with X-Culture to provide real-life business challenges as the focus for the virtual exchanges. Taras believes that the cooperation with the business community makes the initiative more practical and motivating for students, and also provides the corporate partners with creative solutions to their challenges (personal correspondence, 26th of June, 2017). 
The model works in the following way: students from the participating classes are put into GVTs which usually involve six students from different countries. They are then assigned real international business challenges such as designing a marketing strategy for a company which is collaborating with X-Culture. These challenges usually involve different tasks such as carrying out a survey of key stakeholders, an industry and competition analysis, and market selection and analysis, etc.

The students then spend the semester working on those assignments. Teachers receive regular reports on students' work and progress and, upon successful completion of the exchange, students receive X-Culture certificates. Although the requirements and deadlines of the final report are outlined in detail, the international student teams are allowed to choose their online communication tools and can decide themselves about how to coordinate their team work and how the workload should be distributed. In reference to the decision not to use one specific online platform for the exchanges, Taras explains:

"We made a decision not to use a proprietary platform [e.g. Moodle, Canvas, etc.] for communication. Instead, we provide our students with a training on how to use the available online collaboration and communication platforms, such as Dropbox, Google Docs, Slack, Trello, and the like. The students can choose to communicate only via email or Skype, but we teach them how to use these more powerful and free platforms and most teams use these more advanced tools. The logic here is that (1) there is no point in trying to develop our own platform when there are [a] number of extremely powerful tools [that] are already available, and (2) we want our students to be able to use the tools they used in X-Culture even after the project is over" (personal correspondence, 26th of June, 2017).

The model is based on an interesting combination of services provided by the X-Culture platform itself and the work of the teachers who have involved their students in the exchange. For example, although most of the coordination, online communication, and performance monitoring are managed centrally by X-Culture, teachers are asked to regularly communicate with their students and provide coaching and guidance. Teachers are also expected to integrate the exchange into their normal teaching and to devote a small amount of time in each lecture to discuss student progress and to address concerns and answer questions. They are also expected to assess the students' final projects which they submit at the end of their virtual exchange.

The model differs from many other virtual exchange initiatives in that X-Culture collects the online interactions of the students and makes this available to colleagues who wish to carry out research on the data. A significant body of research is now beginning to emerge from the platform which looks at issues such as study GVTs, international collaboration, and experiential learning (http://x-culture. 
org/publications-etc/). Teachers are encouraged to get involved as research collaborators and coauthors of these publications, thereby creating a rich community of both research and practice.

The project website provides some interesting insights into how the X-Culture model is continuing to grow and diverge. For example, various symposia have been held at conferences and on the premises of corporate partners. These symposia are attended by both teachers and students and give participants an opportunity to meet face-to-face with their virtual team partners.

\subsection{Shared syllabus approaches to virtual exchange: COIL}

Although it has been less well documented and researched, educators in other subject areas apart from foreign language education and business studies have also been engaging their students in virtual exchange initiatives since the beginnings of the internet. Their motivation has been to give students in different universities the opportunity to develop a wide range of skills, including intercultural competence and critical thinking, while working on shared subject content and also providing them with different cultural perspectives on their particular subject area (StarkeMeyerring \& Wilson, 2008).

There are a growing number of examples of practitioners from different subject areas who are introducing virtual exchange into their classrooms. Vallance, Martin, and Naamani (2015), for example, report on a project which engaged Japanese undergraduate students and UK high school pupils in online collaboration to design and programme robots in both the real world and in virtual world simulations.

However, in the area of the shared syllabus approaches to virtual exchange, there is one particular approach which has become dominant, and that is the COIL Institute for Globally Networked Learning in the Humanities. Although this approach has existed for many years, as we have seen, the COIL model as it is known today has been developed since 2004 by Jon Rubin and his colleagues at the State University of New York (SUNY) network of universities (Rubin, 2016). Basically, the COIL approach to virtual exchange involves connecting two or more classes of similar course content in different countries. Once connected, the instructors in the partner universities design course modules in a way that the two different student populations will engage in communication and collaboration together. Often, the two groups of students have to work together to discuss course materials, solve a problem of practice, or produce another type of grade-able product. Collaboration may occur synchronously (in real time) or asynchronous (not in real time) and students may connect via email, voice, video, or in some combination (https://nafsatechmig.com/resources/coil/). The key difference between COIL exchanges and those that come from the foreign language or business 
studies traditions of virtual exchange is undoubtedly the emphasis which is put on examining different cultural and national experiences or interpretations of subject content. While foreign language telecollaboration, for example, usually takes language and culture as the content and focus of an exchange, COIL adds a collaborative and comparative perspective to the subject content by creating a 'shared syllabus' which is worked on by all participating classes.

Of course, as is the case with subject specific virtual exchange, there is no one definitive COIL methodology. For example, in their volume which reports various COIL projects, Schultheis Moore and Simon (2015) present examples of courses which are completely online and others which are blended in nature. They also include courses which have negotiated a complete common syllabus and assignments, but they also report on projects which only come together to work on one particular assignment. In recent years, COIL has become one of the largest virtual exchange networks. There are currently 34 university members in the SUNY Global Partner Network and these are engaged with other institutions in collaborative projects. Rubin reports that from 2006 to 2016, COIL also worked more occasionally with an additional 30-40 universities and that they are presently supporting at least 65 joint COIL courses, serving well over 2,500 students (personal interview, 2016).

Although there is relatively little reported research on the learning outcomes of the COIL model, various reports of how the model works and examples of good practice are available. Rubin (2016) provides a broad introduction to the volume and its impact to date, while the volume by Schultheis Moore and Simon (2015) provides a fascinating overview of examples of online exchange initiatives in the Humanities which have stemmed from the work of the COIL Centre. Contributions to this volume provide examples of how the shared curriculum model can be integrated effectively into the study of subject areas as diverse as jazz music, feminism, the diaspora, gender roles, and human rights.

\section{4. 'Service-provider' approaches to virtual exchange - iEARN, Soliya, and Sharing Perspectives}

Until now we have looked at virtual exchange initiatives which have emerged from the work of individual teachers. However, there is an important field of work being carried out by organisations which are dedicated to providing the curricula and online environments (and even, in some cases, the educators) which universities may need to engage their students in virtual exchange.

This 'service-provider' approach to virtual exchange is actually quite common at all levels of education and various groups and organisations have been providing ready-made virtual exchange environments for primary and secondary education for many years. The oldest of these organisations is iEARN, a non-profit organisation which was founded in 1988 and is currently made 
up of over 30,000 schools and youth organisations in more than 140 countries. iEARN reports that over 2,000,000 students each day take part in their projects worldwide. The organisation offers over 150 pre-designed projects and provides online environments where educational institutions can sign on, choose the project which best suits their students' curriculum, and then participate with international partner classes to complete the activities.

Although iEARN cater principally for students in pre-university education, there are various other virtual exchange organisations which attend exclusively to higher education institutions. In contrast to the practitioner-driven approaches which generally rely on the teachers of the classes to organise and lead the exchange, these providers use 'facilitator-led' models which involve trained intercultural educators leading the online discussions and facilitating the intercultural learning. One of the best-known of these models is the Soliya Connect programme, which brings students from the west into dialogue with students from the Muslim world with the aim of developing a deeper understanding of the perspectives of others around the world on important socio-political issues and also to develop critical thinking, intercultural communication, and media literacy skills (Helm, 2015).

Each iteration of the project connects more than 200 students from more than 30 different universities in the US, Europe, and the predominantly Arab and/or Muslim worlds. Students are placed into small groups and guided through an eight-week, English language dialogue programme by pairs of trained facilitators. Students receive credit from their local institution for participating in the project, even though the facilitators and the online exchange environment are contracted from the Soliya organisation by the different universities.

Since being established in 2003, Soliya has worked with well over a 100 institutions, and have over 10,000 activated alumni from 28 countries. They have also trained over 1,300 young people to work as professional online facilitators since 2003. Although the initiative started as an attempt to promote West/Arab dialogue in the aftermath of the September 2001 attacks in the US, Soliya has gone on to broaden its curriculum in order to attend to other areas, such as 21st century skills (e.g. crosscultural communication, collaborative problem solving, team work, etc.) that enable participants to engage with differences more positively and to become active global citizens.

Soliya's virtual exchange programme contains various characteristics which make it differ to 'traditional' class-to-class virtual exchange set ups which we have seen until now. Firstly, communication takes place through synchronous video conferencing on a specially-designed platform. Students take part in a two-hour videoconference every week for eight weeks and this makes up the core of the programme. Students are allocated into small groups of eight to ten for interaction, 
if possible with an equal division between participants from the west and the predominantly Arab and Muslim world so that they can be exposed to a multiplicity of diverse viewpoints. However, the most distinctive of the Soliya's characteristics is undoubtedly the role of the facilitator who takes part in all the online sessions and whose role it is to create a safe dialogic space for learning and to ensure that the dialogue process is constructive and meaningful.

Soliya also follows a structured eight-week programme which ensures that, as relationships develop, participants are able to explore difficult conversations and gain critical awareness on their peers and themselves in the process. The Soliya curriculum also has clear education goals and a specific structure to help groups reach their learning objectives and to ensure that certain learning components on cross-cultural communication are a part of everyone's dialogue process. However, the format of the curriculum is semi-structured, thereby providing space for each group to discuss issues that are important to those young people in question.

Finally, the online interface that is used by Soliya in its virtual exchange programmes has been especially designed to facilitate online synchronous group interaction. This ensures that the technology facilitates diverse dialogue and supports inclusive discussions where everyone is able to be heard.

Another example of a virtual exchange 'service provider' has been pioneered by the Sharing Perspectives Foundation, which is a non-profit organisation dedicated to providing students and academics with opportunities to collaboratively study contemporary themes related to the subjects of political science, law, economics, and social science. Although the Sharing Perspectives model has evolved greatly in recent times, their approach usually contains the following elements:

- Providing academic content: participating universities construct a shared curriculum which is presented through video lectures by the participating educators.

- Online discussion: after watching the video lecture assigned for that particular week, students come together in subgroups - of one student per participating university - in a web-based video conferencing room. Here, they discuss the lecture of that week. These discussions are hosted by professionally trained facilitators.

- Engaging in collaborative research: students are then required to collaboratively design, conduct, and share survey research about the topic in their own communities to learn about the broader societal impact of the topic (Sharing Perspectives).

An example of a Sharing Perspectives project is Perspectives on the Euro(pean) Crisis, which involved eight partner universities with funding from the European Commission. The project explored the 
causes of and possible solutions to the European crisis and was structured around the major economic, political, and sociocultural challenges that were at stake in the European Union. The exchange lasted 16 weeks and included two video lectures a week, mostly contributed by the partner universities; a two-hour weekly dialogue session with eight to ten students from each university in the group which was led by trained facilitators; and a research component, with participants carrying out three surveys and gathering responses from peers and young people in their countries. Selected participants from each university were then invited to Brussels to present the research results. Students who successfully complete Sharing Perspectives projects are usually awarded 5 European Credit Transfer and Accumulation System (ECTS) for their work by their local institutions.

\section{Recent developments in virtual exchange}

Undoubtedly one of the main barriers to the development of virtual exchange has been the general lack of awareness of the educational value of the activity by educational decision makers and funding organisations. However, recent years have seen various developments which would suggest that the activity is growing in importance.

In 2011, various virtual exchange organisations including the Global Nomads Group, iEARN-USA, and Soliya came together with other organisations to form the Virtual Exchange Coalition in order to promote the activity as a distinctive area of learning and as an essential tool in 21st century education. Since its formation, the Coalition has actively lobbied on behalf of virtual exchange across the globe and it has seen various milestones, including when the Education and Scientific Research Office of the League of Arab States endorsed virtual exchange programming in a communique to all Arab Ministers of Education in 2011 and when the Educational and Cultural Affairs Bureau of the US State Department (the world's largest funder of physical exchange) established a Virtual Exchange Unit in 2013. Finally, in the Asian context, the Asia Pacific Virtual Exchange Association (APVEA) has been established to promote virtual exchange initiatives in that region.

In the European context, the European Commission has provided funding for various research initiatives related to telecollaboration and virtual exchange. For example, between 2011 and 2014, the Integrating Telecollaborative Networks in Higher Education (INTENT) project was financed by the European Commission to achieve greater awareness of telecollaboration around the academic world and to look for ways for its integration into university education. One of the main outcomes of this project was the UNICollaboration platform where university educators and mobility coordinators can establish partnerships and find the resources necessary to set up telecollaborative exchanges. Since then, UNICollaboration has established itself as an academic organisation and holds regular 
bi-annual UNICollaboration conferences for practitioners from all disciplines who are interested in virtual exchange.

The European Commission has financed several other virtual exchange projects, including EVALuating and Upscaling telecollAborative Teacher Education (EVALUATE) which is a European policy experiment that will study the impact of virtual exchange on students in initial teacher education across Europe as well as Evidence-Validated Online Learning through Virtual Exchange (EVOLVE), which aims to promote virtual exchange across higher education.

More recently, the European Commission also published a large scale feasibility study on the potential of virtual exchange and, following this, launched Erasmus+ Virtual Exchange (EVE), a flagship programme which aims to expand the reach and scope of the Erasmus ${ }^{+}$programme via virtual exchange. During 2018, EVE aims at engaging over 8000 participants from Europe and the South-Mediterranean in an engaging and safe online community where young people can participate in facilitated discussions, increase their intercultural awareness, and extend their linguistic (currently English, and soon French and Arabic) and communicative competences. The programme offers learners a wide range of virtual exchange initiatives and is currently implemented by a consortium of organisations led by Search for Common Ground and which includes UNICollaboration.

\section{Conclusion and future perspectives}

The review of different virtual exchange initiatives and models which has been presented here provides an insight into the great variety and richness of work which is currently going on in the field. Of course, on a general level, all the initiatives can be seen to share a basic educational approach which involves a commitment to experiential learning, collaborative critical enquiry, and cross-curricular learning (Cummins \& Sayers, 1995); and all would also share common educational goals such as the development of transversal skills, digital literacies, intercultural awareness, and the ability to live and work together with people from other cultural backgrounds (Guth \& Helm, 2010). Many of the initiatives also appear to have encountered the same problems and challenges as they seek to expand their practice to greater numbers of classrooms and institutions. These include students having limited access to technology, teachers' limited digital competences, time-differences hindering synchronous communication, and institutional resistance to the inter-institutional approach to learning which virtual exchange can involve (O’Dowd, 2013; Starke-Meyerring \& Wilson, 2008, p. 223). 
Differences between the models emerge at the level of organisational structure behind the initiatives. There is a clear difference, for example, between practitioner-led approaches such as the foreign language telecollaboration models outlined above, shared syllabus approaches such as COIL, and the service-provider initiatives such as Soliya and Sharing Perspectives. Inevitably, each approach can be seen to have its strong and weak points. Practitioner-led initiatives are developed by teachers who believe passionately in the underlying principles and aims of virtual exchange and therefore these models are likely to grow in a slow, but steady bottom-up fashion. On the other hand, approaches such as COIL, which involve both management and teaching faculties, will benefit from the institutional support supplied by university management and are likely to receive the funding and training necessary to integrate virtual exchange on a large scale across an institution. However, the belief and support of senior management alone cannot guarantee the passionate belief and motivation of the teaching staff to this approach to learning. Finally, service provider approaches offer a valuable service to educational institutions, providing their students with well-designed frameworks of trained facilitators, partnerships, and tasks which they can access without needing staff from the institutions themselves to be knowledgeable in this area. In this sense, they provide an excellent supplementary educational resource which can complement students' regular studies without actually needing to be integrated into course syllabi. However, these initiatives are likely to have serious issues of sustainability as they continue to grow in popularity.

Inevitably, it is likely that virtual exchange will continue to grow in different directions, depending on practitioner-driven, institutionally-led and outsourced initiatives. The important issue is that the practitioners and promoters of these different forms of virtual exchange work closer together to promote the overall goal of increasing the number of students who benefit from online intercultural exchange as part of their university education.

The future of virtual exchange appears to be bright yet still unclear in many respects. Issues such as students' access to technology and teachers' lack of digital competences remain serious problems in many parts of the globe. Furthermore, while it is clearly beginning to gain recognition at national and transnational policy-making levels, there is still a need for greater communication and coordination among the many initiatives and organisations, and this undoubtedly hinders the further dissemination of this educational approach among the wider academic community. Agreeing to use one term, such as Virtual Exchange, may be a first step in the right direction, but even this proposal is likely to be rejected by some of the practitioners and organisations mentioned in this article. Further steps may include organising joint conferences and research initiatives with representatives of all the initiatives and organisations mentioned here. The bi-annual UNICollaboration conference is one example of such an initiative. It is also hoped that this journal will also contribute to bringing virtual exchange researchers and practitioners from a wide range of subject areas together. In any case, 
although progress may be slow, it is clear that, in a world increasingly characterised by the rise of right-wing extremism, religious fanaticism, and populist political movements, virtual exchange will have an important role to play as educators strive to develop active, informed, and responsible citizens who are tolerant of difference and who are actively engaged in political and democratic processes.

\section{Acknowledgement}

Part of the research of this article was made possible by funding from the EVALUATE Erasmus+ Key Action 3 project. EVALUATE (582934-EPP-1-2016-2-ES-EPPKA3-PI-POLICY) is funded by Erasmus+ Key Action 3 (EACEA No 34/2015): European policy experimentations in the fields of education, training and youth led by high-level public authorities. The views reflected in this document are the authors' alone and the commission cannot be held responsible for any use which may be made of the information contained therein.

The author would like to thank the representatives of COIL, Soliya, Sharing Perspectives, and $\mathrm{X}$-Culture who gave interviews which were used in this article. He would also like to thank the two reviewers of the article for their suggestions and feedback.

\section{References}

Belz, J. (2001). Institutional and individual dimensions of transatlantic group work in network-based language teaching. ReCALL, 13(2), 213-231. https://doi.org/10.1017/S0958344001000726a

Belz, J. (2002). Social dimensions of telecollaborative foreign language study. Language Learning \& Technology, 6(1), 60-81. http://www.lltjournal.org/item/2373

Belz, J. (2003). Linguistic perspectives on the development of intercultural competence in telecollaboration. Language Learning \& Technology, 7(2), 68-99. http://www.lltjournal.org/item/2423

Belz, J. (2005). Telecollaborative language study: a personal overview of praxis and research. Selected Papers from the 2004 NFLRC Symposium. http://nflrc.hawaii.edu/networks/nw44/belz.htm

Belz, J. A., \& Thorne, S. L. (2006). Internet-mediated intercultural foreign language education. Thomson Heinle.

Bower, J., \& Kawaguchi, S. (2011). Negotiation of meaning and corrective feedback in Japanese/English Etandem, Language Learning \& Technology, 15(1), 41-71. http://www.lltjournal.org/item/2723

Cummins, J., \& Sayers, D. (1995). Brave new schools. Challenging cultural literacy through global learning networks. St. Martin's Press.

Donath, R., \& Volkmer, I. (Eds). (1997). Das Transatlantische Klassenzimmer. Koerber-Stiftung. 
Dooly, M. (2016). 'Please remove your avatar from my personal space': competences of the telecollaboratively efficient person. In R. O’Dowd \& T. Lewis (Eds), Online intercultural exchange: policy, pedagogy, practice (pp. 192-208). Routledge.

Duus, R., \& Cooray, M. (2014). Together we innovate: cross-cultural teamwork through virtual platforms. Journal of Marketing Education, 36(3), 244-257. https://doi.org/10.1177/0273475314535783

Eck, A., Legenhausen, L., \& Wolff, D. (1995). Telekommunikation und Fremdsprachenunterricht: Informationen, Projekte, Ergebnisse. AKS-Verlag.

European Commission. (2017). Study on the feasibility of an erasmus+ virtual exchange initiative: final report. European Commission. https://ec.europa.eu/education/sites/education/files/erasmus-virtual-exchange-study_en.pdf

Furstenberg, G., Levet, S., English, K., \& Maillet, K. (2001). Giving a virtual voice to the silent language of culture: the culture project. Language Learning \& Technology, 5(1), 55-102. http://www.lltjournal.org/item/2342

Guth, S., \& Helm, F. (Eds). (2010). Telecollaboration 2.0: language, literacies and intercultural learning in the 21st Century. Peter Lang. https://doi.org/10.3726/978-3-0351-0013-6

Hauck, M., \& MacKinnon, T. (2016). A new approach to assessing online intercultural exchange: open badges for soft certification of participant engagement and task execution. In R. O’Dowd \& T. Lewis (Eds), Online intercultural exchange: policy, pedagogy, practice (pp. 209-234). Routledge.

Heller, R., Laurito, A., \& Johnson, K. (2010). Global teams: trends, challenges and solutions. https://est05.esalestrack.com/ eSalesTrack/Content/Content.ashx?file=4578f59e-21b3-4a2c-bbfe-63e53af3f5dc.pdf

Helm, F. (2015). A dialogic model for telecollaboration. Bellaterra Journal of Teaching \& Learning Language \& Literature, 6(2), 28-48.

Kern, R., Ware, P., \& Warschauer, M. (2008). Network-based language teaching. In N. H. Hornberger (Ed.), Encyclopedia of language and education (pp. 1374-1385). Springer. https://doi.org/10.1007/978-0-387-30424-3_105

Leone, P., \& Telles, J. A. (2016). The teletandem network. In R O’Dowd \& T. Lewis (Eds), Online intercultural exchange: policy, pedagogy, practice (pp. 241-247). Routledge.

Lindner, R. (2016). Developing communicative competence in global virtual teams: a multiliteracies approach to telecollaboration for students of business and economics. CASALC Review, 1, 144-156.

Navracsics, T. (2016). Engage - why we need to open up education more than ever. Third dialogue with Southern Mediterranean countries on Higher Education. Brussels. Speech cited in Study on the feasibility of an erasmus+ virtual exchange initiative: final report (p. 24). European Commission. https://ec.europa.eu/education/sites/education/files/ erasmus-virtual-exchange-study_en.pdf

O'Dowd, R. (2006). Telecollaboration and the development of intercultural communicative competence. Langenscheidt.

O’Dowd, R. (Ed.). (2007). Online intercultural exchange: an introduction for foreign language teachers. Multilingual Matters.

O’Dowd, R. (2013). Telecollaboration and CALL. In M. Thomas, H. Reindeers, \& M. Warschauer (Eds), Contemporary computer-assisted language learning (pp. 123-141). Bloomsbury Academic.

O’Dowd, R. (2015). The competences of the telecollaborative teacher. The Language Learning Journal, 43(2), 194-207. https://doi.org/10.1080/09571736.2013.853374 
O'Dowd, R. (2017). Virtual Exchange and Internationalising the Classroom. TLC Journal - Training Language \& Culture, 4(2), 8-27. http://www.icc-languages.eu/component/attachments/download/136

O’Dowd, R., \& Lewis, T. (Eds). (2016). Online intercultural exchange: policy, pedagogy, practice. Routledge.

O’Rourke, B. (2007). Models of telecollaboration (1): E(tandem). In R. O’Dowd (Ed.), Online intercultural exchange: an introduction for foreign language teachers (pp. 41-62). Multilingual Matters.

Osland, J., Bird, A., Maznevski, M., McNett, J., Mendenhall, M., Scholz, C., Stein,V., \& Brunner, D. (2004). Global reality with virtual teams: lessons from the geographically distant multicultural teams project. In C. Wankel \& R. De Fillippi (Eds), The cutting edge of international management: research in man-agement education and development (pp.115-141). Information Age Publishing.

Rice, C. (2005). IECC: intercultural email classroom connections, a history. http://uniyatra.blogspot.com.es/2005/03/ieccintercultural-email-classroom.html

Riel, M. (1997). Learning circles make global connections. In R. Donath \& I. Volkmer (Eds), Das Transatlantische Klassenzimmer (pp. 329-357). Koerber-Stiftung.

Rubin, J. (2016). The collaborative online international learning network. In R. O’Dowd \& T. Lewis (Eds), Online intercultural exchange: policy, pedagogy, practice (pp. 263-272). Routledge.

Schultheis Moore, A., \& Simon, S. (2015). Globally networked teaching in the humanities. Routledge.

Starke-Meyerring, D., \& Wilson, M. (Eds). (2008). Designing globally networked learning environments: visionary partnerships, policies, and pedagogies. Sense Publishers.

Taras, V., Caprar, D. V., Rottig, D., Sarala, R. M., Zakaria, N., Zhao, F., Jiménez, A., Wankel, C., Weng, S. L., Minor, M., Bryła, P., Ordeñana, X., Bode, A., Schuster, A. M., Vaiginiene, E., Froese, F. B., Bathula, H., Yajnik, N., Baldegger, R., \& Huang, V. Z. Y. (2013). A global classroom evaluating the effectiveness of global virtual collaboration as a teaching tool in management education. Academy of Management Learning and Education, 12(3), 414-435.

Tella, S. (1991). Introducing international communications networks and electronic mail into foreign language classrooms: a case study in Finnish senior secondary schools. Yliopistopaino.

Thorne, S. (2010). The intercultural turn and language learning in the crucible of new media. In S. Guth \& F. Helm (Eds), Telecollaboration 2.0: language and intercultural learning in the 21st century (pp. 139-165). Peter Lang.

Vallance, M., Martin, S., \& Naamani, C. (2015). A situation that we had never imagined: post-Fukushima virtual collaborations for determining robot task metrics. Internaional Journal of Learning Technology, 10(1), 30-49.

Vilmi, R. (1994). Global communication through email: an ongoing experiment at Helsinki University of Technology. Paper presented at TESOL 94 Conference, Paris. http://www.hut.fi/ rvilmi/Publication/global.html

Vinagre, M., \& Muñoz, B. (2011). Computer-mediated corrective feedback and language accuracy in telecollaborative exchanges. Language Learning \& Technology, 15(1), 72-103. http://www.lltjournal.org/item/2724

Warschauer, M. (Ed.). (1995). Virtual connections: online activities \& projects for networking language learners. Second Language Teaching \& Curriculum Center, University of Hawaii at Manoa. https://files.eric.ed.gov/fulltext/ED406824.pdf Warschauer, M. (Ed.). (1996). Telecollaboration in foreign language learning. Second Language Teaching and Curriculum Center, University of Hawai'i at Manoa. 
Published by Research-publishing.net, a not-for-profit association Voillans, France, info@research-publishing.net

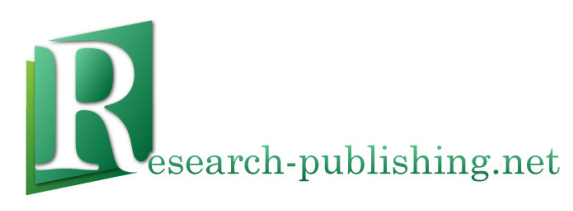

Journal of Virtual Exchange (JVE) is an online, open-access, peer-reviewed journal aimed at practitioners and researchers in the field known variously as virtual exchange, telecollaboration, or online intercultural exchange. It is the official journal of UniCollaboration (https://www.UniCollaboration.org/), the international academic organisation dedicated to supporting and promoting telecollaboration and virtual exchange in higher-level education.

Disclaimer. Research-publishing.net does not take any responsibility for the content of the pages written by the authors of this article. The authors have recognised that the work described was not published before, or that it was not under consideration for publication elsewhere. While the information in this article is believed to be true and accurate on the date of its going to press, neither UniCollaboration nor Research-publishing.net can accept any legal responsibility for any errors or omissions. Additionally, the publisher makes no warranty, expressed or implied, with respect to the material contained herein. While Research-publishing.net is committed to publishing works of integrity, the words are the authors' alone.

Trademark notice. Product or corporate names may be trademarks or registered trademarks, and are used only for identification and explanation without intent to infringe.

Copyrighted material. Every effort has been made by the editorial team to trace copyright holders and to obtain their permission for the use of copyrighted material in this article. In the event of errors or omissions, please notify the publisher of any corrections that will need to be incorporated in future editions of this article.

Typeset by Research-publishing.net

Noto fonts are open source. All Noto fonts are published under the SIL Open Font License, Version 1.1. Noto is a trademark of Google Inc. (https://www.google.com/get/noto/).

ISSN: in process (online only) 